\title{
Potencial osteoindutor da matriz óssea homóloga desmineralizada de coelho
}

\author{
Osteoinductivity of demineralized homologous bone graft in rabbits
}

\author{
Ricardo Junqueira Del Carlo Alessandra Maria da Silva Marlene Isabel \\ Vargas Viloria Cláudio Cézar Fonseca Damaris Rizzo Oliveira
}

\section{RESUMO}

$O$ trabalho objetivou avaliar o potencial osteoindutor da matriz óssea homóloga (MOD) desmineralizada em ácido clorídrico. Em doze coelhos adultos, foi realizada uma incisão sagital mediana na pele abdominal, de aproximadamente $5 \mathrm{~cm}$, e a divulsão do tecido subcutâneo, permitindo que três fragmentos de MOD, com $1 \mathrm{~cm}$ de comprimento, fossem implantados em "bolsas" confeccionadas cirurgicamente no músculo reto abdominal. A MOD foi preparada a partir de rádios de coelhos sacrificados por superdosagem anestésica e estocada em etanol $70 \%$, em temperatura ambiente, por, no mínimo, 15 dias, até o momento do uso. Para permitir análise prévia às enxertias, fragmentos de MOD preservados em etanol $70 \%$ e fixados em formol a $10 \%$ tamponado foram submetidos à rotina histológica. Quatro coelhos foram sacrificados a cada duas, quatro e seis semanas de pós-operatório. A rotina histológica foi realizada, também, em dois dos enxertos implantados em cada animal, em cortes longitudinais e transversais, corados por $H \& E$ e no fragmento restante a deposição de osso novo foi evidenciada pela fluorescência da tetraciclina administrada aos animais. Os resultados da pesquisa permitiram concluir que o ácido clorídrico 0,6 $\mathrm{N}$ promoveu desmineralização eficaz e manteve o potencial indutor da matriz óssea; a imersão da matriz óssea desmineralizada em etanol $70 \%$ propiciou a esterilização dos enxertos homólogos e não inibiu o potencial osteoindutor; e também que, a MOD, devido a fatores indutores inerentes que atuam sobre as células dos tecidos adjacentes, promoveu quimiotaxia, mitose e diferenciação celular.

Palavras-chave: reparação óssea , osso desmineralizado, enxerto ósseo.

\begin{abstract}
In order to evaluate osteoinduction of the homologous demineralized bone matrix (DBM), $1 \mathrm{~cm}$ radial fragments were demineralized in HCL $0.6 \mathrm{~N}$ solution for 24 hours, preserved in $70 \%$ ethanol solution and implanted in the abdominal musculature of 12 adult rabbits. The animals were sacrificed at 2, 4 and 6 post-operative weeks. After euthanasia, macroscopic, miroscopic and tetracycline fluorescence exams were performed. At four weeks, the implants already presented calcification signs. Microscopically, there was mature bone and medulary canal with hematopoietic cells, at six weeks. There was no evidence of rejection, or fluorescence at two and four weeks; at six weeks, there was difuse and concentric bands fluorescence. DBM in HCL $0.6 \mathrm{~N}$ solution and preserved in ethanol $70 \%$ solution maintains its osteoinductive property and remains sterile.
\end{abstract}

Key words: bone reparation, demineralized bone, bone graft.

\section{INTRODUÇÃO}

Os tipos celulares que constituem o osso se originam das células tronco que dão origem a duas populações de células osteogenicamente competentes: as células osteoprogenitoras determinadas (COPD), que se diferenciam em células osteogênicas, assegurando o crescimento, a manutenção, a remodelação e a reparação ósseas; e as células

${ }^{1}$ Médico Veterinário, Doutor, Professor Titular, Departamento de Veterinária (DVT), Universidade Federal de Viçosa (UFV), 36570000, Viçosa, MG. E-mail: ricarlo@ufv.br. Autor para correspondência.

${ }^{2}$ Médico Veterinário, Mestre, União Educacional do Planalto Central, UNIPLAC, DF.

${ }^{3}$ Médico Veterinário, Doutor, Professor Adjunto, DVT, UFV.

${ }^{4}$ Médico Veterinário, Mestrando, DVT, UFV. 
osteoprogenitoras indutíveis (COPI), que precisam de um fator indutor para se diferenciar (BANKS, 1992). As COPIs, que somente se diferenciarão para formar osso sob a influência de um fator indutor, podem ser encontradas no tecido conjuntivo em geral e também na medula óssea. Podem participar da osteogênese heterotópica e influenciam processos reparativos (BRIGHTON et al., 1992).

A matriz óssea é constituída por componentes inorgânicos e por orgânicos, que são tradicionalmente divididos em colágeno e proteínas não colágenas. Os fatores de crescimento ósseo consistem em menos de $1 \%$ das proteínas não colágenas (LIND, 1998), são produzidos pelos osteoblastos e incorporados na matriz extracelular durante a formação óssea, mas pequenas quantidades podem ser removidas do soro e incorporadas à matriz. Os fatores de crescimento estão localizados dentro da matriz até que a remodelação ou o trauma causem sua solubilização e liberação(URIST, 1994; LIND, 1998).

Durante o processo de reparação óssea, os fatores de crescimento têm importantes funções tanto na iniciação quanto na manutenção da diferenciação e proliferação das células osteoprogenitoras e dos osteoblastos que contribuem para a formação do osso novo (LIND, 1998). As proteínas ósseas morfogenéticas (BMPs) são expressas durante as fases precoces da reparação óssea, e o seu carreador é a matriz colágena, a matriz óssea desmineralizada e as várias matrizes polissacarídicas sintéticas (WOSNEY, 1994).

A desmineralização da matriz óssea (MOD) expõe as proteínas osteoindutoras, podendo, de fato, ativá-las. Comparações clínicas diretas do sucesso do tratamento usando enxertos homólogos mineralizados e desmineralizados produzem resultados similares, embora o padrão do primeiro seja osteocondutor, enquanto o desmineralizado é considerado osteoindutor (SCHWARTZ et al., 1998).

A função da matriz parece ser a imobilização da proteína osteoindutora em um sítio particular por um tempo suficiente para que ocorra a indução óssea (WOSNEY, 1994). Como a MOD não apresenta atividade osteogênica, a formação óssea que ocorre se deve à influência osteoindutora exercida pela matriz implantada (TULI \& SINGH, 1978).

LANE \& SANDHU (1987) caracterizaram os fenômenos indutivos manifestados pela MOD como uma cascata seqüencial de eventos inter-relacionados semelhantes ao que ocorre durante a ossificação endocondral. Observaram que, histologicamente, a formação óssea intramembranosa pareceu ser o evento predominante, com áreas de ossificação endocondral na interface osso receptor e implante.
Diversas causas podem explicar os diferentes resultados clínicos quando o tratamento com MOD é utilizado. Uma causa potencial pode ser o fato de que as proteínas osteoindutoras estão presentes, mas em quantidade insuficiente para eliciar formação óssea detectável, ou elas estão em uma forma inativa. Outra pode estar associada a diferentes técnicas de processamento do material e, ou, a características do doador (SCHWARTZ et al., 1998). Presumivelmente, quanto mais minerais são removidos da MOD, mais BMPs tornam-se expostas e solubilizadas, e como resultado, o osso corretamente desmineralizado é maximamente osteoindutor (ZHANG et al., 1997).

A musculatura apresenta características vasculares com capacidade de fornecer células tronco mesenquimais, que permitem o início da formação óssea em resposta aos fatores osteogênicos existentes no enxerto homólogo transplantado (BROWN et al., 1997; SOLHEIM, 1998).

Este trabalho teve por objetivo avaliar o potencial osteoindutor da matriz óssea homóloga desmineralizada em ácido clorídrico, após implantação em sítio heterotópico, considerando o conceito de WHITE \& SHORS (1986) os quais afirmaram que, quando o implante é colocado em tecido mole e a formação óssea que ocorre evidencia diferenciação celular, ele é dito osteoindutor.

\section{MATERIAL E MÉTODOS}

O experimento foi conduzido no Departamento de Veterinária da Universidade Federal de Viçosa, em doze coelhos adultos da raça Nova Zelândia Branco. O protocolo anestésico consistiu de pré-anestesia com acepromazina $^{\mathrm{a}}(0,2 \mathrm{mg} / \mathrm{kg}, \mathrm{IV}) \mathrm{e}$ anestesia dissociativa com tiletamina/zolazepam ${ }^{\mathrm{b}}$ (15 $\mathrm{mg} / \mathrm{kg}$, IV). Cada coelho recebeu $40.000 \mathrm{UI} / \mathrm{kg}$, IM, de penicilina $\mathrm{G}$ benzatina ${ }^{\mathrm{c}}$, logo após a medicação préanestésica. Após os procedimentos cirúrgicos, os animais foram alojados individualmente em gaiolas, recebendo ração comercial e água ad libitum.

A MOD foi preparada a partir de rádios de coelhos sacrificados por superdosagem anestésica. Todo o tecido mole foi removido do osso, com bisturi e sem uso de produto químico. Os ossos foram desmineralizados por imersão em ácido clorídrico, em temperatura ambiente; o osso foi considerado totalmente desmineralizado quando se apresentava mole, transparente e flexível. A MOD foi estocada em etanol 70\%, em temperatura ambiente, por, no mínimo, 15 dias, até o momento do uso.

Objetivando análise prévia às enxertias, fragmentos de MOD preservados em etanol $70 \% \mathrm{e}$ 
fixados em formol a $10 \%$ tamponado foram submetidos à rotina histológica. Os cortes confeccionados foram corados por H\&E e avaliados, em microscopia óptica, quanto às características teciduais.

Os animais foram posicionados em decúbito dorsal e preparado o campo operatório. Uma incisão sagital mediana na pele abdominal, de aproximadamente $5 \mathrm{~cm}$, e a divulsão do tecido subcutâneo, permitiram que três fragmentos de MOD, com $1 \mathrm{~cm}$ de comprimento e envolvendo todo o diâmetro do rádio, fossem implantados em "bolsas" confeccionadas cirurgicamente no músculo reto abdominal, sendo duas no lado direito e uma no esquerdo, distantes $1 \mathrm{~cm} \mathrm{da}$ linha média e com $2 \mathrm{~cm}$ de afastamento entre si.

Quatro coelhos foram sacrificados a cada duas, quatro e seis semanas de pós-operatório. À época das necropsias, os implantes foram observados quanto ao tamanho e consistência, presença de encapsulamento e evidências de calcificação.

A rotina histológica foi realizada, também, em dois dos enxertos implantados em cada animal, em cortes longitudinais e transversais, corados por H\&E e examinados ao microscópio óptico. Foram avaliadas a presença de reação inflamatória, encapsulamento, tecido condro/osteóide e tecido medular.

Para o exame da fluorescência da tetraciclina, todos os coelhos receberam $30 \mathrm{mg} / \mathrm{kg}$ de oxitetraciclina ${ }^{\mathrm{d}}$, IM, por três dias consecutivos. O mesmo protocolo foi repetido após intervalo de uma semana. Os coelhos foram sacrificados 48 horas após a última aplicação, e o material foi processado segundo técnica preconizada por VOLPON (1985). O material foi examinado em fotomicroscópio de fluorescência por epiiluminação, com filtro triplo $\mathrm{DFE}^{\mathrm{e}}$ e fotografado. A deposição de osso novo no espaço de tempo determinado foi evidenciada pela fluorescência.

\section{RESULTADOS}

$\mathrm{Na}$ avaliação microscópica realizada antes da implantação, a MOD apresentou-se eosinofílica, homogênea e com baixa celularidade e as células presentes apresentaram alterações nucleares do tipo cariólise, cariorrexe e picnose (Figura 1).

À necropsia, todos os enxertos implantados foram recuperados sem diminuição de tamanho e estavam bem incorporados ao tecido adjacente. $\mathrm{Na}$ segunda semana, foi possível visualizar um delicado revestimento cápsulo-fibroso. Inicialmente, o enxerto não mostrava sinais macroscópicos de calcificação, apresentando consistência semelhante à da MOD. Na sexta semana, o enxerto apresentava-se rijo e rangia ao corte com navalha, demonstrando indícios de focos de calcificação.

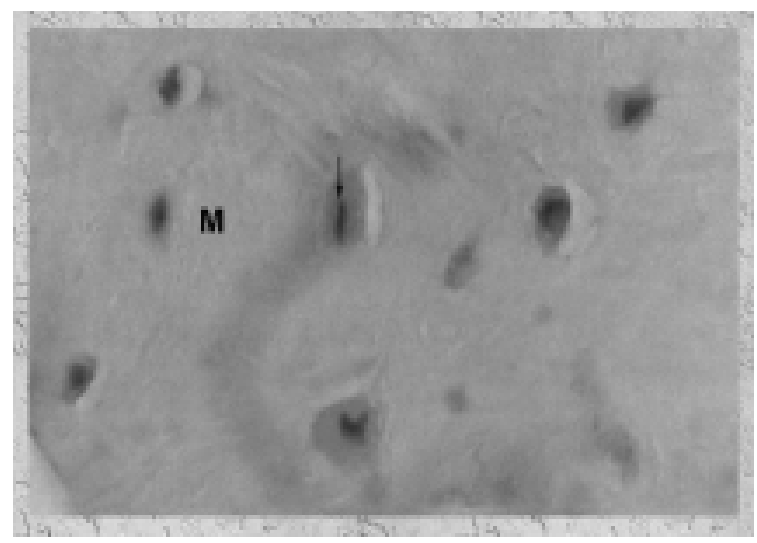

Figura 1 - Aspecto microscópico da matriz óssea desmineralizada antes da implantação: matriz (M) eosinofílica e homogênea, contendo células com características de necrose, como picnose (seta). H\&E. 400X.

Histologicamente, na segunda semana de pós-operatório, os enxertos conservavam a forma cilíndrica, sendo constituídos por cortical e canal medular, e estavam revestidos por tecido conjuntivo fibroso aderido à superfície (Figura 2A). Não foram observadas características de reação inflamatória do tipo corpo estranho. Células gigantes multinucleadas já iniciavam o processo de reabsorção da periferia do implante. A matriz implantada tinha aspecto coagulado e raros corações condróides no seu interior, os quais ocupavam principalmente os antigos canais vasculares, que também estavam preenchidos por células blásticas em sua maioria. O canal medular apresentava formação de cartilagem aderida à matriz e estava preenchido por tecido conjuntivo fibroso e por células blásticas estreladas (Figura 3), por outras que pareciam ser da linhagem hemocitopoiética e por grande quantidade de hemácias.

Com a evolução (quatro e seis semanas), mais corações condróides se evidenciavam e osteoblastos preenchiam os canais de Havers e Volkmann, que se apresentavam alargados e continham células multinucleadas, semelhantes a osteoclastos, que fagocitavam a matriz (Figura 4A). A incorporação do enxerto foi evidente (Figura 2B), com a penetração de vasos sanguíneos na matriz. Foi possível observar células semelhantes a fibroblastos, porém apresentavam núcleo ovóide e menos basofílico, que pareciam células indiferenciadas ou em processo de desdiferenciação, localizadas no interior da MOD implantada (Figura 4B). Havia áreas de formação óssea, mais na periferia do implante, compostas por trabéculas irregulares revestidas por osteoblastos, notando-se, também, áreas de matriz osteóide que preenchiam praticamente toda a região ocupada pelo enxerto 


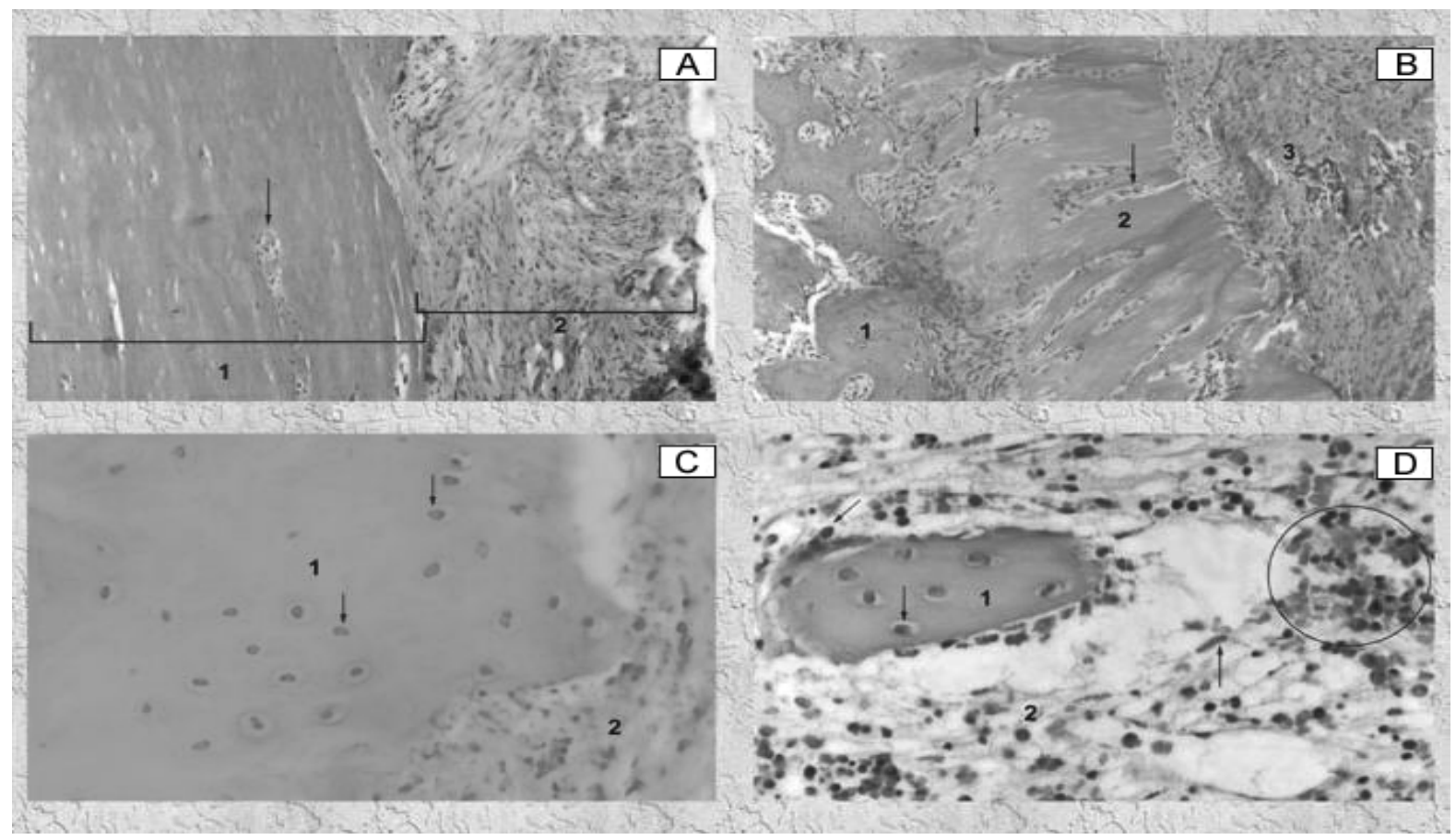

Figura 2 - Aspecto microscópico do processo de formação óssea. Em A, corte longitudinal da matriz óssea implantada, na segunda semana de pós-operatório: MOD (1); tecido conjuntivo fibroso (2); invasão dos canais vasculares por células indiferenciadas do tecido receptor (seta). Em B, corte transversal do implante na quarta semana: novo osso (1); restos da MOD (2); penetração da matriz por células indiferenciadas do tecido receptor (setas); tecido conjuntivo fibroso (3). H\&E. 100X. Em C, corte transversal do novo osso formado (1) na sexta semana: osteoblastos ativos (setas); medula (2). Em D, corte transversal da região medular na sexta semana: trabécula óssea (1) com osteoblastos ativos (seta negra); célula gigante multinucleada (seta dentro do quadrado); medula (2); célula indiferenciada (seta dentro do círculo), células da linhagem hemocitopoiética (círculo). H\&E. 400X.

(Figura 2C). A ossificação intramembranosa foi predominante na periferia do implante. A cavidade medular apresentava fibras reticulares, vasos sanguíneos e tecido hemocitopoiético (Figura 2D).

$\mathrm{Na}$ segunda e quarta semanas após a enxertia, predominou a ausência de fluorescência específica. Posteriormente, na sexta semana, predominavam áreas fluorescentes amorfas acompanhadas por lamelas fluorescentes. As áreas amorfas corresponderam ao primeiro protocolo de tetraciclina e a formação de osso imaturo, e as lamelas, ao segundo protocolo, caracterizando osso maduro. $\mathrm{O}$ espaço entre estas duas camadas de fluorescência correspondia à semana de intervalo entre as duas aplicações do antibiótico.

\section{DISCUSSÃO}

Apesar do mecanismo da desmineralização pelo ácido clorídrico ser pouco conhecido (LEEWANDROWSKI et al., 1997), a sua utilização a 0,6 $\mathrm{N}$ mostrou-se eficiente, tornando-o um método viável, de baixo custo, rápido e prático, como observado por TULI \& SINGH (1978), e não destruiu o potencial osteoindutor da MOD, além de não ter ocorrido reação inflamatória do tipo corpo estranho. Entretanto, outros ácidos utilizados no experimento de NADE \& BURWELL (1977), alteraram as propriedades bioquímicas da matriz ou evocaram reação do tipo corpo estranho.

A preservação em etanol $70 \%$ mostrou-se eficaz, já que não foi observada qualquer infecção decorrente de contaminação e, provavelmente, não alterou as características bioquímicas da matriz, indicando o poder de esterilização deste álcool e, ao mesmo tempo, sua inocuidade para a matriz e suas proteínas (URIST, 1994; BROWN et al., 1997).

A MOD apresentou-se mole, flexível e transparente, assim como observaram TULI \& SINGH (1978). Microscopicamente, foi observado uma matriz colagenosa, eosinofílica e sem evidências de deposição mineral, mas, ao contrário dos relatos de VAIL et al. (1994), não apresentou acelularidade, e sim baixa celularidade. No entanto, as células presentes não pareciam viáveis devido às alterações nucleares. Acredita-se que a alta concentração de ácido clorídrico tenha inviabilizado as células, removendo a capacidade osteogênica do enxerto, mas conservando a capacidade 


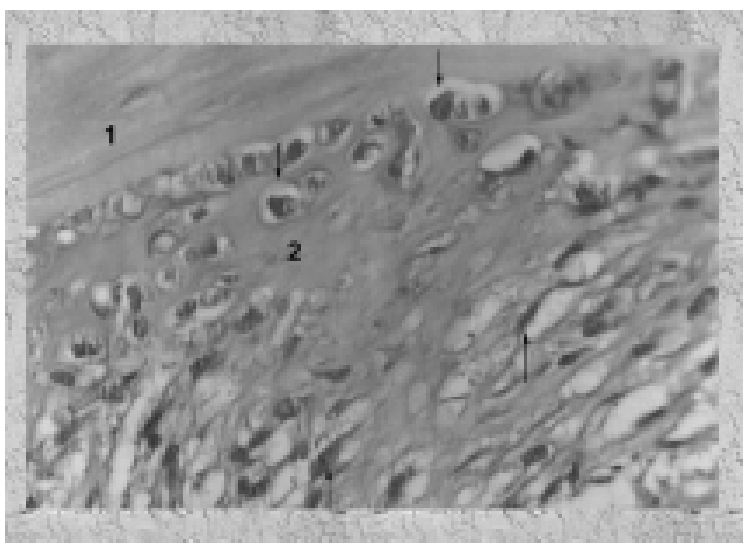

Figura 3 - Aspecto microscópico do corte longitudinal da MOD implantada, na segunda semana de pós operatório: matriz (1); deposição de cartilagem na periferia da matriz (2); condrócitos (setas dentro dos quadrados); células blásticas estreladas (setas negras). H\&E. 400X.

osteoindutora, como comprovaram os resultados histológicos, que, por sua vez, corroboram a afirmação de AICHELMANN-REIDY \& YUKNA (1998) que, atualmente, somente a MOD e BMP homólogas cumprem esse papel.

Assim como HOSNY \& SHARAWY (1985), foi observado que as células atraídas para a matriz foram capazes de invadir sua estrutura colagenosa, possivelmente devido à secreção de enzimas proteolíticas, que digerem a matriz e criam fendas por onde as células migram. E, segundo TULI \& SINGH (1978), a medula vazia, os canais haversianos e os espaços lacunares ofereceram canais permeáveis, que foram ocupados de forma instantânea pelas células tronco reparadoras.

Os enxertos implantados no músculo abdominal foram recuperados da mesma forma e com os mesmos tamanhos, ao contrário dos dados de URIST \& DOWELL (1968), que afirmaram não haver explicação para que seus implantes, apesar de terem perdido tamanho, tenham mantido a forma. Pode-se inferir que este processo foi típico de reabsorção e substituição por tecido ósseo induzido pela presença da MOD.

É possível afirmar que a formação óssea se deveu à capacidade osteoindutora da MOD e mais especificamente da BMP, pois, apesar de a MOD conter vários fatores de crescimento, segundo SOLHEIM (1998), as BMPs são os únicos fatores conhecidos que provocam esta formação óssea, por estimularem as células tronco a se diferenciarem em osteoblastos. Também WOSNEY (1994) observou que a implantação de BMP na forma de MOD produziu resultados equivalentes à implantação de BMP pura, in vivo.

Os enxertos recuperados da musculatura abdominal estavam bem incorporados ao tecido adjacente, e, como foi observado por HOSNY \& SHARAWY (1985), estavam inicialmente envolvidos por um fino envoltório de tecido fibroso, que, segundo os autores, pode ter participado na osteo e condrogênese, por ter provido um pool de células osteoprogenitoras que foram atraídas à MOD implantada, provavelmente por um fator quimiotático derivado do tecido ósseo.

A formação de tecido hemocitopoiético no interior dos implantes pode ser explicada pela teoria da

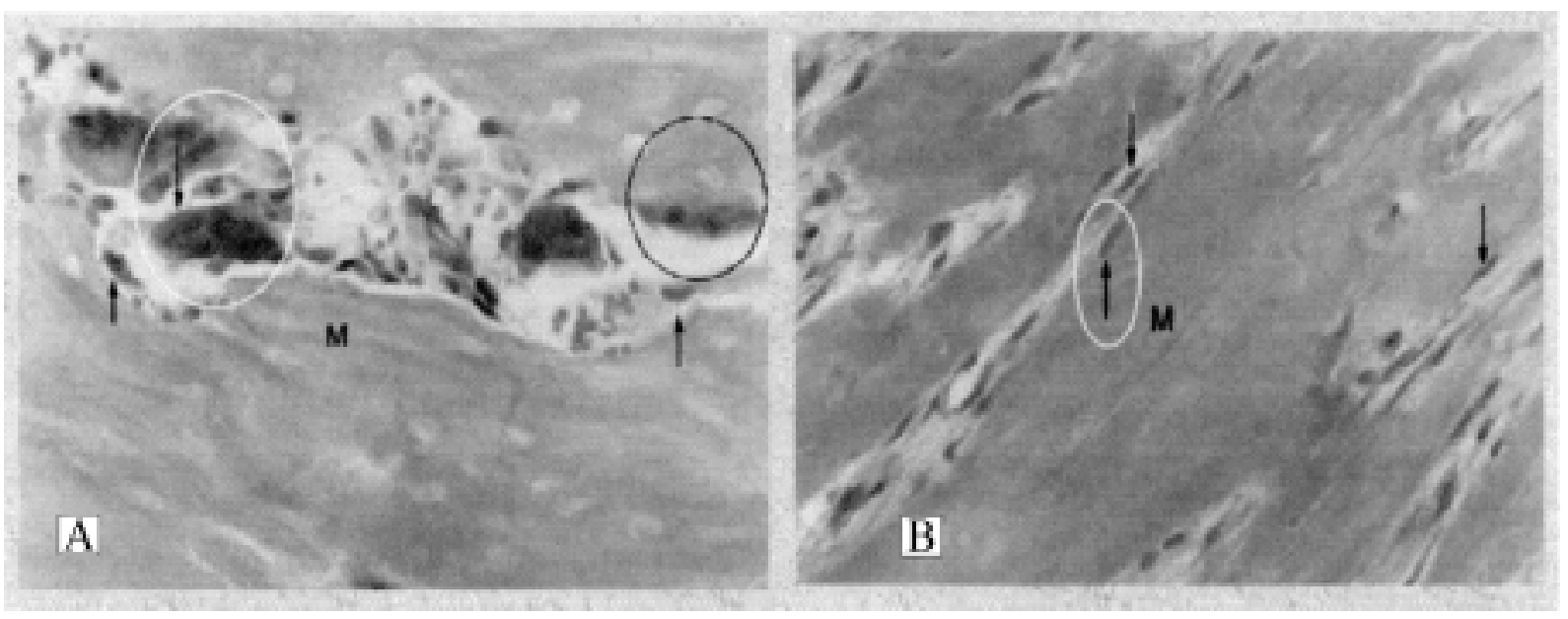

Figura 4 - Aspecto microscópico da incorporação da MOD implantada, na quarta semana de pós-operatório. Em A, corte transversal: canal vascular com numerosas células gigantes multinucleadas (seta dentro do círculo); matriz (M); osteoclasto absorvendo a matriz (círculo); células blásticas (setas). Em B, corte longitudinal: invasão dos espaços vazios da matriz implantada por células do hospedeiro: fibroblastos (setas); células de núcleo ovóide e menos basofílico, provavelmente em processo de desdiferenciação (seta dentro do círculo). H\&E. 400X. 
desdiferenciação citada por NATHANSON (1985). Fatores de crescimento não específicos do tecido ósseo, em microambiente favorável à formação de medula no interior do implante, podem ter agido não só sobre células mesenquimais, diferenciando-as, mas também sobre células de fenótipo pouco rígido, determinando um processo de desdiferenciação seguido pela rediferenciação em células precursoras da linhagem hemocitopoiética.

Esta teoria também pode ter implicação na origem das células osteoprogenitoras indutíveis, as quais podem vir de uma desdiferenciação dos fibroblastos oriundos da cápsula de tecido conjuntivo fibroso que envolveu a MOD implantada.

A tetraciclina possui uma molécula grande que se liga aos microcristais minerais durante o processo de deposição óssea, e nesta pesquisa, ficou evidente sua afinidade pela fração inorgânica do osso, pois a matriz orgânica não apresentou qualquer tipo de fluorescência. Na forma como foi utilizada, permitiu avaliar o crescimento ósseo referente ao período total de aplicação, que correspondeu aos três dias da primeira aplicação do antibiótico, aos sete dias de intervalo e aos três dias da última administração, determinado formações ósseas maduras e imaturas.

\section{CONCLUSÕES}

Com base nos resultados desta pesquisa, pode-se concluir que o ácido clorídrico $0,6 \mathrm{~N}$ promove desmineralização eficaz e mantém o potencial indutor da matriz óssea. A imersão da matriz óssea desmineralizada em etanol $70 \%$ propicia a esterilização dos enxertos homólogos e não inibe o potencial osteoindutor. E também que a MOD devido a fatores indutores inerentes que atuam sobre as células dos tecidos adjacentes, promove quimiotaxia, mitose e diferenciação celular.

\section{FONTES DE AQUISIÇÃO}

a. Acepran 1\%, Univet. São Paulo, SP.

b. Zoletil 50, Virbac.São Paulo, SP.

c. Penicilina G benzatina, Eurofarma. São Paulo, SP.

d. Terramicina injetável, Pfizer. Rio de Janeiro, RJ.

e. Nikon Eclipse E600.

\section{REFERÊNCIASBIBLIOGRÁFICAS}

AICHELMANN-REIDY, M.E.; YUKNA, R.A. Bone replacement grafts: the bone substitutes. Dent Clin North Am, v.42, n.3, p.491-503, 1998.

BANKS, W.J. Tecidos de sustentação: osso. In: BANKS, W.J. (Ed). Histologia veterinária aplicada. 2. ed. São Paulo : Manole, 1992. p.137-186.
BRIGHTON, C.T. et al. The pericyte as a possible osteoblast progenitor cell. Clin Orthop, n.275, p.278-299, 1992.

BROWN, D.M. et al. Osteochondral allografts with an intramedullary muscle flap in rabbits. Clin Ortop, n..334, p.282-290, 1997.

HOSNY, M.; SHARAWY, M. Osteoinduction in rhesus monkeys using demineralized bone powder allografts. J Oral Maxill Surg, v.43, p.925-931, 1985.

LANE, J.M.; SANDHU, H.S. Current approaches to experimental bone grafting. Orthop Clin North Am, v.18, n.2, p.213-225, 1987.

LEEWANDROWSKI, K. et al. An electron microscopic study on the process of acid demineralization of cortical bone. Calcif Tissue Intern, v.61, n.4, p.294-297, 1997.

LIND, M. Growth factor stimulation of bone healing: effects on osteoblasts, osteotomies, and implants fixation. Acta Orthop Scand, Suppl, v.69, n.283, p.1-37, 1998.

NADE, S.; BURWELL, R.G. Decalcified bone as a substrate for osteogenesis: an appraisal of the interrelation of bone and marrow in combined grafts. J Bone Joint Surg, v.59-B, n.2, p.189-196, 1977.

NATHANSON, M.A. Bone matrix directed condrogenesis of muscle in vitro. Clin Orthop, n.200, p.142-148, 1985.

SCHWARTZ, Z. et al. Ability of commercial demineralized freeze-dried bone allograft to induce new bone formation is dependent on donor age but not gender. J Periodont, v.69, n.4, p.470-478, 1998.

SOLHEIM, E. Osteoinduction by demineralized bone. Intern Orthop, v.22, n.5, p.335-342, 1998.

TULI, S.M.; SINGH, A.D. The osteoinductive property of decalcified bone matrix. J Bone Joint Surg, v.60-B, n.1, p.116-123, 1978.

URIST, M.R. The search for and the discovery of bone morphogenetic protein (BMP). In: URIST, M.R.; OCONNOR, B.T.; BURWELL, R.G. (Eds). Bone grafts, derivates and substitutes. Oxford : Butterworth Heinemann, 1994. p.315361 .

URIST, M.R.; DOWELL, T.A. Inductive substratum for osteogenesis in pellets of particulate bone matrix. Clin Orthop, n.61, p.61, 1968.

VAIL, T.B.; TROTTER, G.W.; POWERS, B.E. Equine demineralized bone matrix: relationship between particle size and osteoinduction. Vet Surg, n.23, p.386-395, 1994.

VOLPON, J.B. A marcação do osso com substâncias fluorescentes. Rev Bras Ortop, v.20, n.5, p.207-210, 1985.

WHITE, E.; SHORS, E.C. Biomaterial aspects of interpore200 porous hydroxyapatite. Dent Clin North Am, v.30, p.49-67, 1986.

WOSNEY, J.M. Molecular biology of the bone morphogenetic proteins. In: URIST, M.R.; OCONNOR, B.T.; BURWELL, R.G. (Eds). Bone grafts, derivates and substitutes. Oxford: Butterworth Heinemann, 1994. p.397-413. 